\title{
Feedback and Assessment in Second Language Education during the COVID-19 and Beyond
}

\author{
Shulin $\mathrm{Yu}^{1} \cdot \mathrm{Hao} \mathrm{Xu}^{2}$
}

Accepted: 16 October 2021 / Published online: 21 October 2021

(C) De La Salle University 2021

Inevitably required in second language education, assessment helps students develop language competence and helps teachers improve instruction. As a crucial component of assessment, feedback is not only an essential pedagogical approach which serves as a follow-up to assessment, but also one of the most influential factors affecting students' achievement (Hattie \& Timperley, 2007). Fundamentally, the field of assessment and feedback is issuedriven, and the central issue that concerns educators and researchers is how assessment should be conducted and how feedback should be provided to facilitate students' language learning.

The central issue, however, has it today that the COVID19 pandemic has witnessed second language education moving online on an unprecedented scale around the world. As a result, many schools are replacing traditional examinations with online assessment and feedback, and both teachers and learners need to readapt themselves to new means, formats, and even contents of feedback and assessment. This shift is not merely some additional use of an online technology that makes distant learning possible. It is more a matter of feedback and assessment per se reformulated in both form and content. Therefore, more

Shulin $\mathrm{Yu}$

shulinyu@um.edu.mo

Hao Xu

xuhaokent@bfsu.edu.cn

1 Faculty of Education, University of Macau, Avenida da Universidade, E33-3007, Taipa, Macau, China

2 Beijing Foreign Studies University, 306, Guo Nei Da Sha, West Campus, 19 Xi San Huan Bei Road, Beijing 100089, China research is needed on the imminent prospect of long-term change in and transformation of how feedback and assessment are received, and perceived.

To respond to such a sudden change, scholars and teachers first need to more closely examine how feedback and assessment have been conducted in the virtual space. For instance, what are the impacts of such change upon the validity and efficacy of assessment and feedback in second language education? In what ways can online feedback and assessment be customized for individual differences in learning needs? Is what teachers assessed still assessable online? Has anything become newly assessable since assessment is now made online? Are there any changes in teacher assessment and feedback practices? Are students giving each other feedback as much as, and as well as, they did in an off-line classroom where, for instance, peer feedback was encouraged and guided? These are just some research questions that we hope to seek answers to through timely, rigorous research endeavours.

Besides those apparently emerging issues that merit investigation, less obvious issues also need to be explored as the entire system of second language education may also be modified and reformulated, given the huge impact of feedback and assessment on second language learning processes and outcomes (Xu \& Liu, 2009). Stake-holders including test-designers, test-takers, and teachers may all need to reconceptualise and validate the practices for online or blended testing/assessment; they need to reconsider the backwash effects of such practices; they need to reexamine the optimal ways of providing, receiving, and negotiating feedback based on such testing/assessment practices. More profoundly, these altered or alternative practices of feedback and assessment would foreseeably lead to changes in the complex systems of second language 
education (Zheng, 2015), including not only the local system of feedback and assessment, but also other systems in relation to learner psychology (Freiermuth \& Zarrinabadi, 2020; Yu et al., 2020) and teacher education (Xu, 2017). Learners may need to adopt new identities as online feedback and assessment become commonplace; they may need to employ new cognitive, metacognitive and social strategies as they process online feedback and undergo online assessment. Teachers, likewise, may need to acquire new techniques of online feedback and assessment and hence assume new roles as facilitators of their students' learning; they may need to reeducate themselves for a kind of new assessment/feedback literacy that is urgently needed in the current situation and beyond.

In response to these crucial issues, the articles in this special issue have explored second language teachers' and learners' beliefs, practices, and experiences with regard to various types of assessment and feedback during the COVID-19. The studies reported in these articles have employed a variety of quantitative and qualitative methodologies and methods, including quasi-experimental research, meta-analysis, questionnaire survey, case study, and narrative inquiry. We believe that the articles in this special issue can provide insights into and thus enhance our understanding of the changing assessment and feedback practices and their impact on student learning in different contexts of second language education during the COVID-19 and beyond.

This special issue has attracted attention from researchers and practitioners in Asian and South Asian countries and regions, Turkey, the USA, and New Zealand. It consists of fifteen empirical studies conducted in different countries and regions including China's Mainland, Hong Kong, Macau, Taiwan, India, Bangladesh, Nepal, and Turkey. Seven of the articles deal with teacher assessment and feedback practices during the COVID-19 pandemic, and they all adopt a qualitative research approach to examine the changes in teacher assessment and classroom feedback practices in different contexts including primary schools, secondary schools, and universities in China, India, Turkey, Nepal and Bangladesh.

The first paper by Zou, Kong, and Lee investigated three Chinese English-as-a-foreign-language (EFL) writing teachers' engagement with online formative assessment during COVID-19 in three universities, and their case study identified three types of teacher engagement: disturbing, auxiliary, and integral, with different physical-cognitive, emotional and social investment in the formative use of educational technology in writing assessment. They also found that writing teachers' beliefs, digital literacies, learning/teaching experiences, and other technological and contextual factors could account for their individualized engagements. The findings of their study have important implications for supporting EFL writing teachers' engagement with online formative assessment. The second paper by Zhang, Yan, and Wang examined the online assessment practices of six EFL teachers in a Chinese university. They particularly focused on the changes in assessment practices in response to needs of a new assessment mode due to the pandemic. They found that a number of factors such as instructional policy, local context, and teachers' teaching experience and reflections had mediated teachers' assessment decisions and methods. The third paper by Jiang and $\mathrm{Yu}$ also adopted a case study approach, collecting multiple sources of data, to examine 16 Chinese EFL teachers' feedback changes during the pandemic. This paper identifies three patterns of changes in teachers' feedback-giving practice: the first pattern was positive changes in teachers' feedback-giving motivation, design, and awareness; the second pattern was reduction in formative feedback activities, and increased feedback workload; the third pattern was unchanged practice, informed by a conception of feedback as information transmission.

While the first three studies are conducted in the Chinese EFL context, the next two papers concern teacher assessment and feedback practices in India, Bangladesh, Nepal, and Turkey. Specifically, the fourth paper by Mahapatra, reporting on a multiple- case study, explored online formative assessment and feedback practices of three ESL teachers working in three universities in India, Bangladesh, and Nepal. The analysis of multiple sources of data including classroom observations, interviews, and documents shows that while all the three teachers were able to engage their students in a number of formative assessment practices, the information obtained from assessments did not seem to inform their subsequent feedback practices. Their studies also revealed individual differences among the three teachers in terms of quality of assessment activities, variety and frequency of formative assessment strategies, and selection and application of digital tools for conducting assessments. The fifth study conducted by Güngör and Güngör is a narrative inquiry into a test-designer's implementation of an online highstakes language proficiency test in Turkey during the COVID-19 pandemic. This paper reports on the test designer's narrative accounts regarding the development of test adaptation and implementation, technology use, and the emerging contradictions for future language testing practices.

Different from the five studies above which were conducted in university settings, the next two articles deal with primary and secondary English teachers' assessment and feedback approaches and strategies. The sixth paper by Yan, Zhang, and Cheng examined teachers' classroombased assessment practices in two primary school contexts. 
They revealed that the potential of classroom-based assessment in facilitating young learners' learning had not been fulfilled, and that the teacher participants failed to elaborate on such objectives and success criteria to their students. They also found that student-involving assessment strategies were less frequently adopted, and that the teachers relied on norm-referenced assessment and evaluative feedback. The seventh paper by $\mathrm{Pu}$ and $\mathrm{Xu}$ investigated how the online assessment practices of seven secondary school teachers from seven regions of China during the COVID-19 pandemic. They collected data such as individual interview, teachers' journals, instructional designs for online teaching, and online classroom observation. They found that the teachers went through a transition from neglecting assessment to overdoing assessment in their online teaching process, and that they did not systematically incorporate online assessment into their online curricula, which might have resulted from teachers' lack of understanding of the nature of online assessment as an intrinsic component of curriculum and a major means of enhancing students' learning.

The second group of articles in this special issue examined learners' online feedback and/or assessment beliefs, practices and experiences and learner psychology as impacted by online feedback and/or assessment. The eighth paper by $\mathrm{Xu}$ used a mixed-methods approach to explore Chinese university students' orientations towards written corrective feedback (WCF) and their use of selfregulated learning (SRL) writing strategies in online English writing courses during the COVID-19. His study shows that during the COVID-19, students generally held positive attitudes towards online WCF, and that they used fewer social behaviour strategies than other strategies. Students' feedback-seeking orientation was found to be positively associated with SRL writing strategies; the online interactions between teachers and students in relation to teachers' feedback motivated students to engage more in their subsequent writing practices. The ninth paper by Tsao, which is a quantitative study, explored how 227 Taiwanese senior high school students' L2 writing self-efficacy affected the level of their engagement with teacher and peer written corrective feedback. Two questionnaires were used in this study: the learner engagement with written corrective feedback scale, and the L2 learners' writing self-efficacy scale. The results showed that the participants self-reported a low-to-moderate level of L2 writing self-efficacy, and that self-efficacy for writing self-regulation was the only variable with predictive power for learner engagement with feedback.

The tenth paper by Reynolds, Kao, and Huang used a quasi-experimental design to examine the effects of perceived feedback source on students' second language writing performance. Two groups of Taiwanese English writers-perceived teacher feedback group and perceived automated feedback group-received feedback on four essays written over an 18-week semester. They found that the perceived automated feedback group outperformed the perceived teacher feedback group on the second and third essays, and that the perceived automated feedback group showed statistically significant differences in writing performance. Their findings suggest that perceptions of the feedback source may have caused these results, and that it should be worthwhile to inform L2 student writers of the feedback source. The eleventh paper by Ma, Wang, and Teng explored the perceived effects of learning-oriented online assessment on L2 students' feedback literacy. Their study shows that while the participants held less favorable opinions of the online mode of learning in promoting feedback literacy, they perceived positively the development of feedback literacy in the aspects of appreciating feedback, developing judgments, and taking actions. The twelfth paper by Yang, Mak, and Yuan investigated a group of student teachers' online feedback experience in relation to their professional learning during the COVID-19 pandemic. Their findings revealed that while online feedback afforded learning opportunities such as the provision and reception of feedback in diverse groups within a safe space, it also created challenges such as limited real-time and extensive feedback. Their paper concludes with pedagogical implications on supporting pre-service teachers' online feedback experience and fostering their adaptive help-seeking strategies in feedback situations as critical and self-regulated learners to contribute to their professional learning.

Two articles in this special issue concern feedback and assessment in the context of English for specific purposes-Business English education. The thirteenth paper by Wang and $\mathrm{Wu}$ reports on a study that investigated business English teachers' belief about online assessment using Q methodology. The findings of this study showed a shared configuration among the business English teachers in three factors: strong belief in performance assessment for business English courses, belief in supportive role of ICT, and belief in assessment as an ongoing process. They interpreted the factors from a systematic approach of assessment and the role of ICT in online teaching. These findings enable teachers to improve the quality of online assessment and raise their awareness of effective use of ICT in online teaching. The fourteenth paper conducted by $\mathrm{Xu}$, Chen, Wang, and Suhadolc investigated the characteristics and effectiveness of teacher feedback on online business English presentations, and also explored EFL learners' attitudes toward teacher feedback. Drawing upon data from transcriptions of teacher feedback on presentation rehearsals, assessment scores, questionnaires, and students' self-reflective journals, the researchers found that 
teacher feedback was focused on both content- and delivery-related components, but that new sub-components were added to delivery-related teacher feedback, such as technology use, timing, and teamwork. It also found that the participants held quite positive attitudes toward teacher online feedback.

The last paper by Lv, Ren, and Xie is a meta-analysis study that investigates the effectiveness of online feedback in L2 writing. Their study synthesizes the results of 17 primary studies reporting on students' English writing quality after online feedback. Their analysis shows that online feedback from teachers/instructors produces a larger effect size than online peer feedback and online automated feedback. This paper contributes to a better understanding of the impact of online feedback on L2 writing, and concludes with implications for L2 writing instruction.

Overall, the studies reported in this special issue showcase pertinent research efforts in describing, analysing, and evaluating the effects of online learning and teaching on assessment and feedback practices in second language education across diverse regional and educational contexts since the outbreak of the COVID-19 pandemic. Researchers have taken the timely initiative to address theoretical, practical and methodological issues that have both emerged in tandem with the drastic changes in the global educational landscape and continued to exist from our previous, normal practices. Looking forward, whilst we may anticipate that certain negative effects should become more enduring than expected, we also look forward to new opportunities that improve as we expand and deepen this line of research. Most importantly, we call for more research endeavours dedicated to further unraveling the nature of feedback and assessment in second language education, both in response to today's changing situations and in its own right.

Our special issue concludes with Icy Lee's reflective article in response to the key issues about feedback and assessment in second language education during the COVID-19. Lee makes immediate reference to what we described in the Call for Papers for this special issue about the key challenge brought by the pandemic: "This shift is not merely some additional use of an online technology that makes distant learning possible. It is more a matter of feedback and assessment reformulated in both form and content." Her article has presented how the editors' call was answered by the research studies reported in this special issue. We thank her for her contribution.

We would also like to thank the editors of The AsiaPacific Education Researcher, who supported our proposal for this special issue as well as the reviewers who generously reviewed the submissions. We would also like to acknowledge the work of our authors, without whom this special issue would not have been possible.

\section{References}

Freiermuth, M. R., \& Zarrinabadi, N. (2020). Technology and the psychology of second language learners and users. Palgrave.

Hattie, J., \& Timperley, H. (2007). The power of feedback. Review of Educational Research, 77(1), 81-112.

$\mathrm{Xu}, \mathrm{H}$. (2017). Exploring novice EFL teachers' classroom assessment literacy development: A three-year longitudinal study. The AsiaPacific Education Researcher, 26(3), 219-226.

$\mathrm{Xu}$, Y., \& Liu, Y. (2009). Teacher assessment knowledge and practice: A narrative inquiry of a Chinese college EFL teacher's experience. TESOL Quarterly, 43(3), 493-513.

Yu, S., Jiang, L., \& Zhou, N. (2020). Investigating what feedback practices contribute to students' writing motivation and engagement in Chinese EFL context: A large scale study. Assessing Writing. https://doi.org/10.1016/j.asw.2020.100451

Zheng, H. (2015). Teacher beliefs as a complex system: English language teachers in China. Springer.

Publisher's Note Springer Nature remains neutral with regard to jurisdictional claims in published maps and institutional affiliations. 